\title{
CHARACTERISATION OF ACTIVATED CHARCOAL, SAWDUST CHARCOAL AND RICE HUSK CHARCOAL AS ADSORBENTS IN WATER TREATMENT
}

\author{
${ }^{1}$ Adebola A. Adekunle, ${ }^{2}$ Ayokunle O. Familusi, ${ }^{3}$ Adedayo A. Badejo, \\ ${ }^{4}$ Olayemi J. Adeosun, ${ }^{5}$ Suhaib A. Arogundade \\ ${ }^{1,2,3}$ Department of Civil Engineering, Federal University of Agriculture, Abeokuta, Nigeria, \\ ${ }^{4}$ Department of Agricultural and Bio-Resources Engineering, Federal University of Agriculture, Abeokuta, Nigeria, \\ ${ }^{5}$ School of Civil Engineering, University of Leeds, Leeds, United Kingdom \\ email: adebolamay@gmail.com \\ Received: October 1, 2020 • Accepted: November 26, 2020
}

\begin{abstract}
This study is an investigation into the characterisation of commercial activated charcoal, sawdust charcoal and rice husk charcoal as adsorbents for water treatment. The ground rice husk and waste sawdust collected, were sieved to obtain a nominal size of $1 \mathrm{~mm}$, washed and oven-dried for 12 hours. The two materials were pyrolyzed in a furnace for 30minutes, and the chars produced were later air-dried. The three charcoals (sawdust charcoal, rice husk charcoal, and the activated charcoal purchased from the market) were all subjected to X-ray Fluorescence (XRF) analysis, Scanning Electron Microscope (SEM) analysis and Energy Dispersive X-ray (EDX) analysis in order to characterise the filter materials. The SEM analysis showed that the three materials developed more pores, which is a property of an adsorbent. Likewise, the XRF and EDX analyses confirm that all the three adsorbents possess larger proportion of Silica, Carbon and Oxygen.
\end{abstract}

Keywords: Adsorbent, charcoal, pyrolysis, water treatment

\section{INTRODUCTION}

An adsorbent is a solid substance used to collect solute molecules from a liquid or gas [1]. Most adsorbents [2] are manufactured (such as activated carbons), but a few, such as some zeolites, occur naturally. Each material has its own characteristics such as porosity, pore structure and nature of its adsorbing surfaces. Activated charcoal or carbon [3], the oldest adsorbent known, is a highly porous, amorphous solid consisting of micro crystallites with a graphite lattice, usually prepared in small pellets or a powder. It is non-polar and cheap. The main drawbacks are that it reacts with oxygen at moderate temperatures and that of the recycling costs. Low cost activated carbon can be produced from agricultural wastes which include sawdust, banana peel, orange peel, coconut shell and rice husks [3]. Most activated carbons are made from raw materials such as nut shells, wood, coal and petroleum, which are high in carbon. Heat is used to activate the surface area of the carbon. Typical surface areas for activated carbons are approximately $1000 \mathrm{~m}^{2} / \mathrm{g}$. However, different raw materials produce different types of activated carbon varying in hardness, density, pore and particle sizes, surface areas, extractable, ash and $\mathrm{pH}[4,5]$. The main objective in the manufacture of granular activated carbon is the development of an optimum pore structure associated with a high surface area with minimum loss of the carbon content through carbonization and oxidation and of a product with sufficient structural strength to withstand normal usage without excessive attrition of the particles [6]. Charcoal is made by pyrolyzing wood or other organic matter such as coconut or rice husks, nut hulls, peat, etc. in earthen kilns, brick ovens, or underground pits. The process involves heating the base material to temperatures of $600-900^{\circ} \mathrm{C}$ in the absence of oxygen. "Activation" of charcoal typically refers to physical or chemical processes designed to increase the reactive surface area of the carbon. Industrial activation processes may use chemicals and/or steam to enhance surface area, although simply heating the material to sufficient temperatures can produce a significantly activated charcoal [7]. The properties of activated carbon produced from activated sludge using sulphuric acid as a chemical activation agent, which include surface area, chemical functional groups and chemical composition reveal that it had an improved adsorption behaviour comparable to those of high performance adsorbents [8], while the work 


\section{Analecta Technica Szegedinensia}

of [9] confirms that activated carbons produced from sawdust are good adsorbents for pesticides. The thrust of this research work is to characterise activated charcoal, sawdust charcoal and rice husk charcoal as adsorbents in water treatment.

\section{MATERIALS AND METHODS}

\subsection{Materials and Equipment Required for the Study}

The materials and equipment used in carrying out this research work include:

- Sawdust (of nominal size $1 \mathrm{~mm}$ )

- Rice Husk (of nominal size $1 \mathrm{~mm}$ )

- Activated Charcoal (of nominal size $2 \mathrm{~mm}$ )

- The X-ray Fluorescence (XRF) analysis equipment (Phillips PW-1800)

- The Scanning Electron Microscope (SEM)/Energy Dispersive X-ray (EDX) analysis equipment

- Furnace (Vecstar product)

- Sieves (of $1 \mathrm{~mm}$ and $2 \mathrm{~mm}$ size)

- Oven.

\subsection{Methods}

\section{Sample Preparation}

The activated charcoal (purchased at Osogbo, Nigeria) was sieved in order to obtain a nominal size of $2 \mathrm{~mm}$. The waste sawdust (collected from a sawmill at Ede, Nigeria) was sieved in order to obtain a nominal size of $1 \mathrm{~mm}$. The rice husk collected was ground and sieved in order to obtain a nominal size of $1 \mathrm{~mm}$. The two materials (sawdust and rice husk) above were washed and later oven-dried at 80degree centigrade for 12 hours as specified by [10]. After the two materials had been dried, they were pyrolyzed in a furnace at temperature $550^{\circ} \mathrm{C}$ for thirty minutes. Then, the char produced was later air-dried.

\section{XRF Analysis}

Sample of activated charcoal was crushed with an electric crusher and then pulverized for 60 seconds using Herzog Gyro-mill (Simatic C7-621). Pellets were prepared from the pulverized sample, first by grinding $20 \mathrm{~g}$ of the sample with $0.4 \mathrm{~g}$ of stearic acid for 60 seconds. After each grinding, the Gyro-mill was cleansed to avoid contamination. $1 \mathrm{~g}$ of stearic acid was weighed into an aluminum cup to act as binding agent and the cup was subsequently filled with the sample to the level point. The cup was then taken to Herzog pelletizing equipment and it was passed at a pressure of $200 \mathrm{KN}$ for 60 seconds. The $2 \mathrm{~mm}$ pellets were added into a sample holder of the X-ray equipment (Phillips PW-1800) for analysis. Two distinct measurements were taken for the analysis. The whole XRF process was also repeated for sawdust charcoal and rice husk charcoal.

\section{SEM and EDX Analyses}

Sample of activated charcoal was placed on the aluminum holder stub using a double sticky carbon tape. The sample was given a conductive coating and electrically grounded. Mark was inscribed on the sample stub for identification. The sample was completely oven-dried at $60^{\circ} \mathrm{C}$ for about 3 hours, and then loaded into the SEM holder of the microscope (JEOLJSM-7600F) for SEM and EDX analyses. Two distinct measurements were taken for the analyses.The whole SEM and EDX processes were also repeated for sawdust charcoal and rice husk charcoal. 


\section{Analecta Technica Szegedinensia}

\section{RESULTS AND DISCUSSION}

\section{XRF Analysis}

The results obtained from XRF analysis of the filter materials are shown in Tables 1 and 2. Table 1 reveals that all the three filter materials selected, contain Silica $\left(\mathrm{SiO}_{2}\right)$, Alumina $\left(\mathrm{AI}_{2} \mathrm{O}_{3}\right)$, Ferric Oxide $\left(\mathrm{Fe}_{2} \mathrm{O}_{3}\right)$, Calcium Oxide $(\mathrm{CaO})$, and other oxides. Loss on ignition (LOI) of about $10 \%$ was found in the sawdust and rice husk charcoals, but was absent in the activated charcoal. This suggests that the LOI is moderate (approximately 10\%) and that the composition of hydrates and volatile materials in the sawdust and rice husk charcoals is moderate. The activated charcoal contains $15 \%$ ash instead of LOI found in the other two forms of charcoals. Table 2 shows that the three forms of charcoals contain trace elements like Barium, Copper, Chromium, Nickel, Zinc, Cobalt, Strontium, Lead, Scandium and Cadmium. Niobium, Rubidium and Zirconium are only found in the sawdust charcoal but not in the other two forms of charcoal.

Table 1: XRF Analysis Showing Concentrations of Oxides in the Charcoals

\begin{tabular}{llll}
\hline \multirow{2}{*}{$\begin{array}{l}\text { Major } \\
\text { Oxides }\end{array}$} & \multicolumn{3}{c}{ Concentration $(\mathrm{Wt} \%)$} \\
\cline { 2 - 4 } & $\begin{array}{l}\text { Activated } \\
\text { Charcoal }\end{array}$ & $\begin{array}{l}\text { Sawdust } \\
\text { Charcoal }\end{array}$ & $\begin{array}{l}\text { Rice Husk } \\
\text { Charcoal }\end{array}$ \\
\hline $\mathrm{SiO}_{2}$ & 80.80 & 80.04 & 80.20 \\
$\mathrm{AI}_{2} \mathrm{O}_{3}$ & 3.03 & 2.11 & 2.00 \\
$\mathrm{Fe}_{2} \mathrm{O}_{3}$ & 0.05 & 0.72 & 0.15 \\
$\mathrm{TiO}_{2}$ & 0.07 & - & 0.20 \\
$\mathrm{CaO}$ & 0.10 & 0.18 & 2.75 \\
$\mathrm{P}_{2} \mathrm{O}_{5}$ & 0.02 & 0.65 & 0.02 \\
$\mathrm{~K}_{2} \mathrm{O}$ & 0.11 & 2.16 & 3.45 \\
$\mathrm{MnO}$ & 0.01 & 0.06 & 0.41 \\
$\mathrm{MgO}$ & 0.01 & 3.12 & 0.01 \\
$\mathrm{Na} 2 \mathrm{O}$ & 0.02 & 0.44 & 0.14 \\
$\mathrm{LOI}$ & - & 10.52 & 10.60 \\
$\mathrm{Ash}$ & 15.60 & - & - \\
\hline
\end{tabular}

Table 2: XRF Analysis Showing Concentrations of Trace Metals in the Charcoals

\begin{tabular}{llll}
\hline \multirow{2}{*}{$\begin{array}{l}\text { Trace } \\
\text { Elements }\end{array}$} & \multicolumn{3}{c}{ Concentration (Ppm) } \\
\cline { 2 - 4 } & $\begin{array}{l}\text { Activated } \\
\text { Charcoal }\end{array}$ & $\begin{array}{l}\text { Sawdust } \\
\text { Charcoal }\end{array}$ & $\begin{array}{l}\text { Rice Husk } \\
\text { Charcoal }\end{array}$ \\
\hline $\mathrm{Ba}$ & 450.60 & 230.1 & 855.60 \\
$\mathrm{Cu}$ & 13.50 & 1.8 & 18.50 \\
$\mathrm{Cr}$ & 12.10 & 1.2 & 12.50 \\
$\mathrm{Ni}$ & 11.50 & 0.3 & 15.80 \\
$\mathrm{Zn}$ & 10.40 & 12.3 & 12.60 \\
$\mathrm{Co}$ & 10.20 & 2.6 & 10.20 \\
$\mathrm{Sr}$ & 7.00 & 1.9 & 4.80 \\
$\mathrm{~Pb}$ & 10.45 & 0.43 & 12.25 \\
$\mathrm{Sc}$ & 7.25 & 0.90 & 10.25 \\
$\mathrm{Cd}$ & 0.14 & 1.1 & 0.02 \\
$\mathrm{Nb}$ & - & 1.5 & - \\
$\mathrm{Rb}$ & - & 1.0 & - \\
$\mathrm{Zr}$ & - & 1.6 & - \\
\hline
\end{tabular}




\section{Analecta Technica Szegedinensia}

\section{SEM Analysis}

The surface morphologies of the filter materials determined using SEM are as shown in Figures 1, 2 and 3. It can be observed from Figures 1, 2 and 3 that more pores were developed in all the filter materials at the magnification of 10,000 times and the adsorbent size is smaller. The three filter materials (charcoals) possess nsmaller pores and approximately the same size. Adsorption is a surface phenomenon; therefore smaller adsorbent particle size offers a comparatively larger and more accessible surface area (more pores developed) in such a typical material (as cited in [10]).

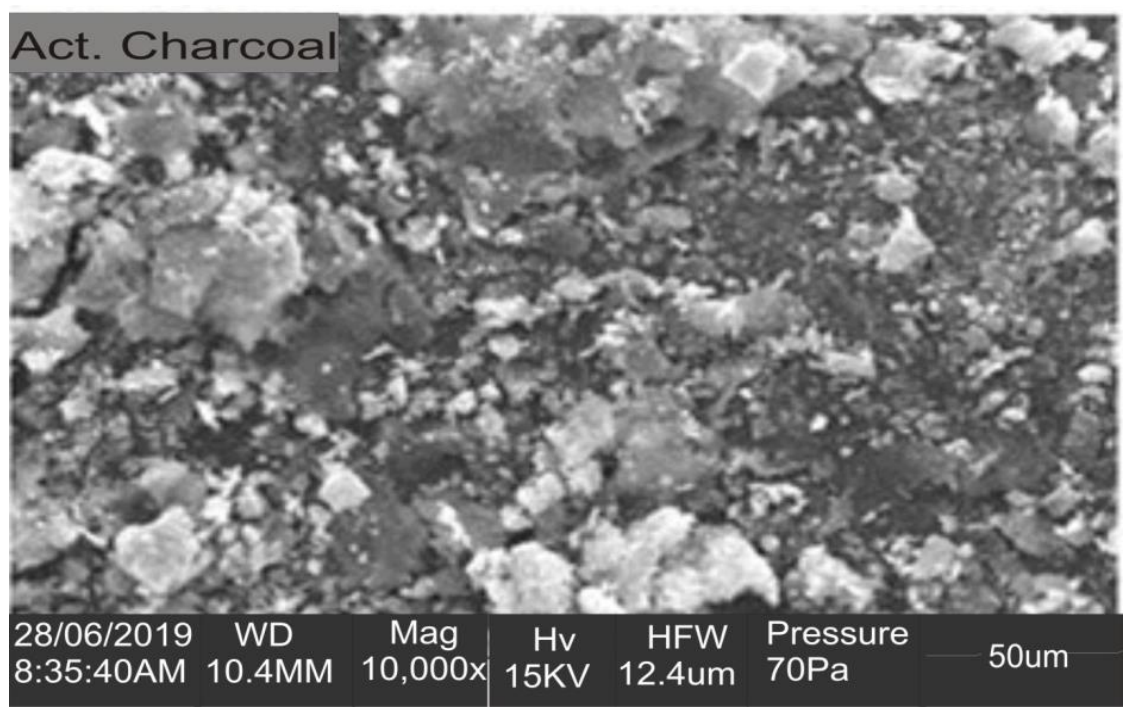

Figure 1: SEM Analysis Showing Surface Morphology of the Activated Charcoal

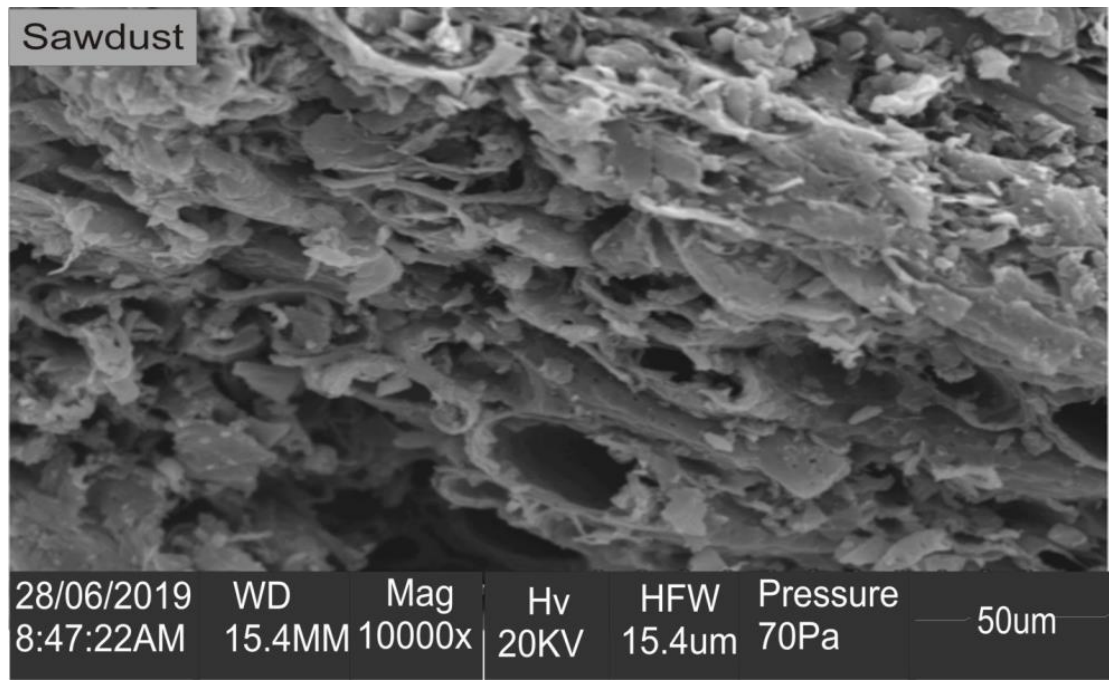

Figure 2: SEM Analysis Showing Surface Morphology of the Sawdust Charcoal 


\section{Analecta Technica Szegedinensia}

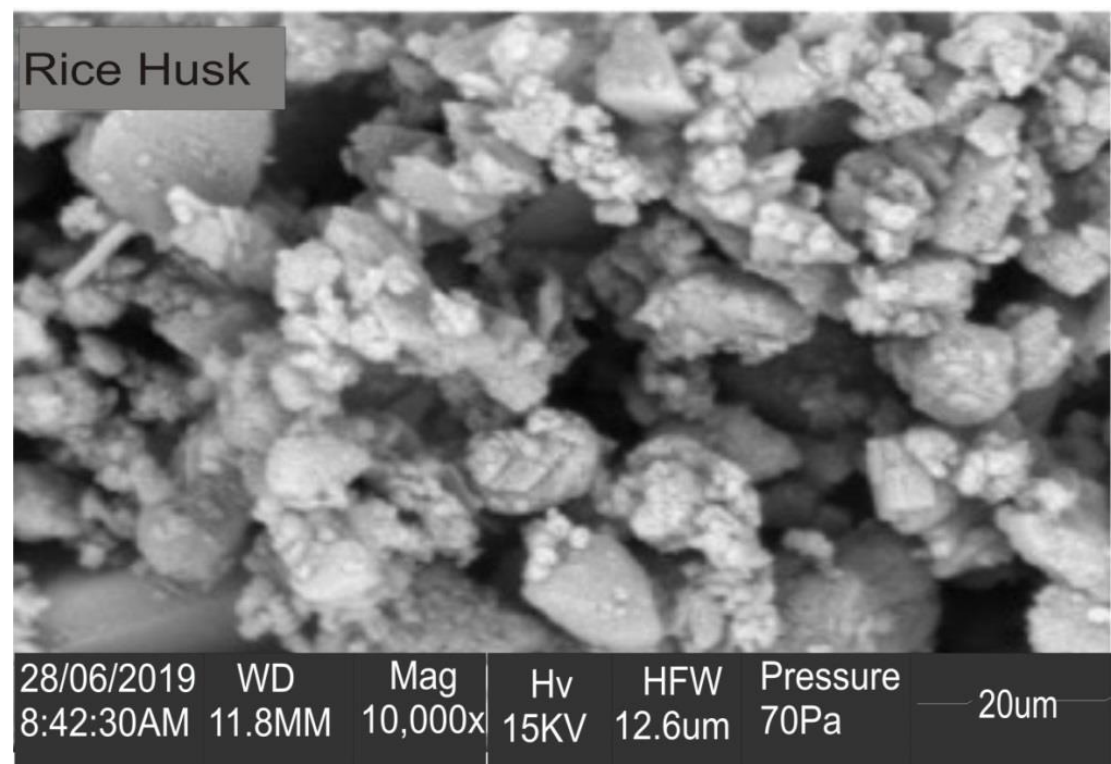

Figure 3: SEM Analysis Showing Surface Morphology of the Rice Husk Charcoal

\section{EDX Analysis}

The EDX results are shown in Figures 4, 5 and 6. Further chemical characterization (that is, EDX analysis) of the activated charcoal shown in Figure 4 revealed that the activated charcoal contains Carbon, Oxygen and Sulphur in descending order. The EDX analysis of the sawdust charcoal as shown in Figure 5 revealed that the sawdust charcoal contains Carbon, Oxygen, Silicon, Potassium, Aluminium and Calcium in descending order while Figure 6 revealed that rice husk charcoal contains Calcium, Silicon, Oxygen, Potassium, Carbon, Chlorine and Chromium in descending order.

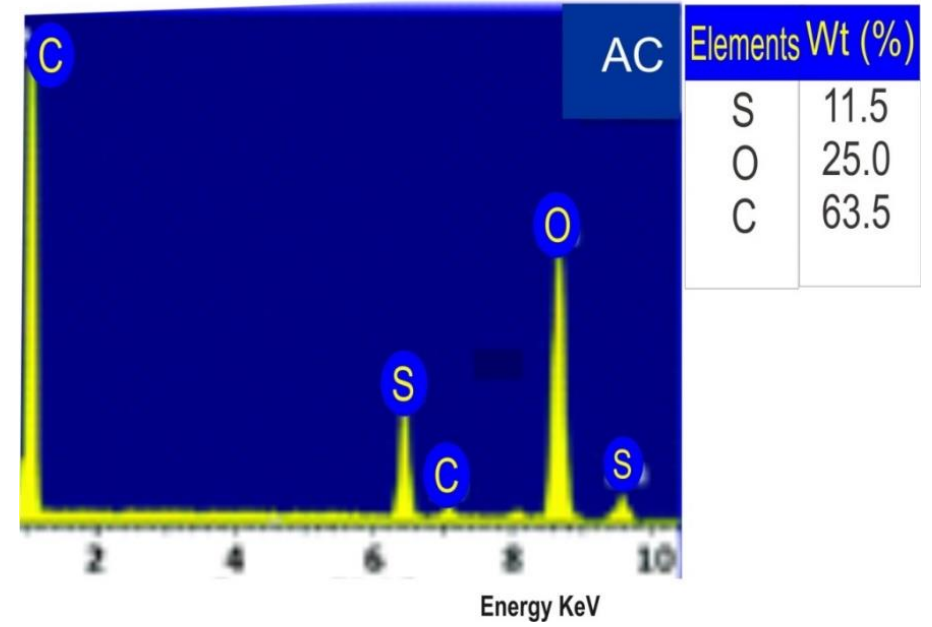

Figure 4: EDX Analysis Showing Chemical Characterisation of the Activated Charcoal 


\section{Analecta Technica Szegedinensia}

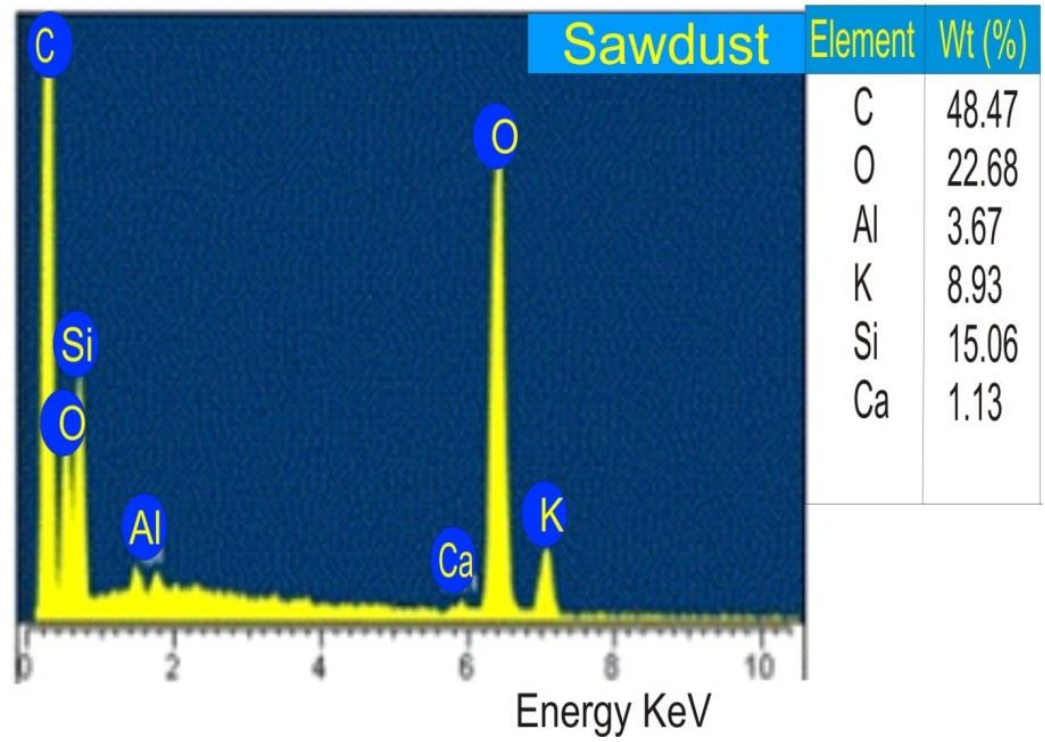

Figure 5: EDX Analysis Showing Chemical Characterisation of the Sawdust Charcoal

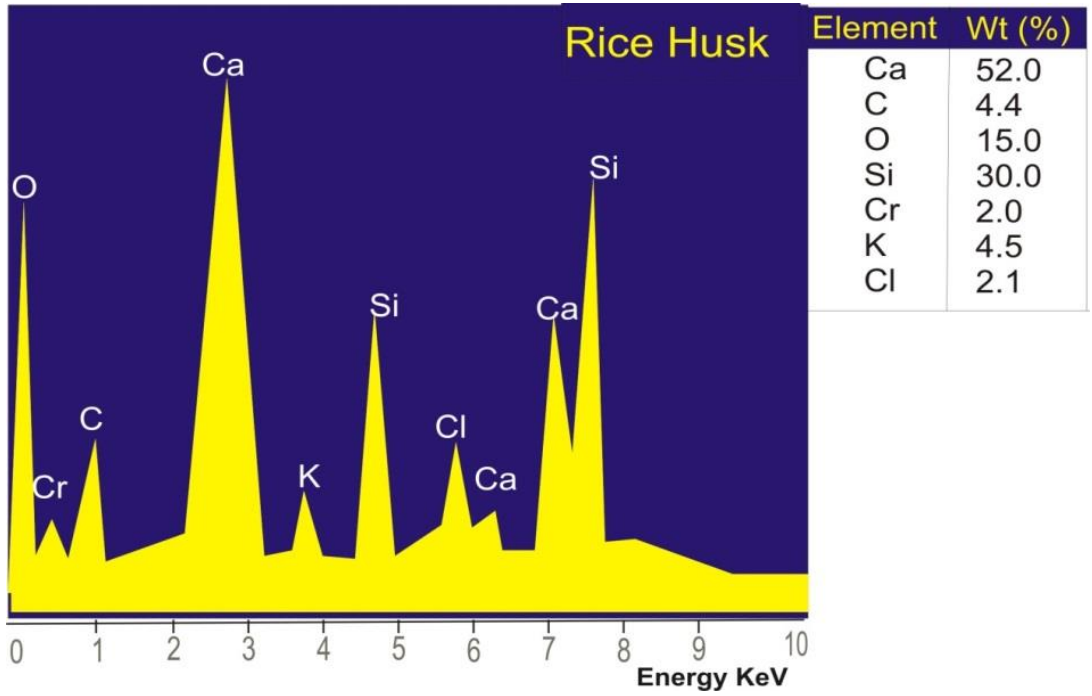

Figure 6: EDX Analysis Showing Chemical Characterisation of the Rice Husk Charcoal

\section{CONCLUSIONS}

All the three filter materials (Activated Charcoal, Sawdust Charcoal and Rice Husk Charcoal) selected possess larger proportion of Silica and Carbon, and they also possess more pores which are typical features of an adsorbent. Silica and Carbon are regarded as natural materials used for water filtration [11]; hence the selected materials are good adsorbents in water or waste water treatment. 


\section{Analecta Technica Szegedinensia}

\section{REFERENCES}

[1] Collins Dictionary, Adsorbents, Retrieved from: https://www.collinsdictionary.com/dictionary/english/adsorbent 2019.

[2] Separation Processes, Adsorbents, Retrieved from: http://www.separationprocesses.com/Adsorption/AD_Chp01a.htm 2019.

[3] S. A. Azeem, Development of New Sorbents for Removal of Contaminants from Water, Retrieved from:

http://www.suswatec.de/download/presentations/Abdelazeem.pdf 2013.

[4] F. J. De Silva, Exploring the Multifunctional Nature of Activated Carbon Filtration, A Publication of Water Quality Products, Retrieved from: htttps://www.waterqp.com 2000.

[5] Minnesota Pollution Control Agency, Granular Activated Carbon Filters, A Publication of Minnesota Pollution Control Agency, Retrieved from: https://www.pca.state.mn.us/sites/default/files/c-s1-05.pdf 2009.

[6] G. J. McDougall, The Physical Nature and Manufacture of Activated Carbon, Journal of the South African Institute of Mining and Metallurgy, 91 (4), 1991, pp. 109-120.

[7] J. Kearns, Charcoal Filtration Basics, A Publication of Aqueous Solutions Drinking Water Systems, Retrieved from: http://www.aqsolutions.org/resources/Charcoal_Filtration.pdf 2007.

[8] Z. Al-Qodah, R. Shawabkah, Production and Characterization of Granular Activated Carbon from Activated Sludge, Brazilian Journal of Chemical Engineering, 26 (1), 2009, pp. 127 - 136.

[9] B. Kakoi, J. W. Kaluli, G. Thumbi, A. Gachanja, Performance of Activated Carbon prepared from Sawdust as an Adsorbent for Endosulfan Pesticide, Journal of Sustainable Research in Engineering, 2 (1), 2015, pp. 1-10.

[10] M. K. Lam, R. Zakaria, Production of Activated Carbon from Sawdust using Fluidized Bed Reactor, International Conference on Environment, Retrieved from: http://www.eprints.usm.my/13227/1/production_of_activated.pdf 2008.

[11] J. Duvauchelle, Natural Materials Used for Water Filtration, Retrieved from: https://www.livestrong.com/article/165592-natural-materials-used-for-water-filtration/ 2019. 